\title{
A vingança sobrenatural em A maldição do canavial, de Claribalte Passos
}

Ivson Bruno da Silva*

Resumo: Este artigo objetiva analisar o conto "A maldição do canavial”, em Estórias de engenho, do escritor pernambucano Claribalte Passos, à luz do fantástico. A partir de teóricos que oportunizam uma leitura do texto em diálogo com o contexto, traça-se um olhar sobre o sobrenatural que deturpa a visão de realidade da personagem e do leitor. Na narrativa, o fantástico se liga aos episódios de injustiça e se configura como maldição, cujas manifestações são os acontecimentos inexplicáveis aos olhos da razão.

Palavras-chave: Literatura fantástica. Sobrenatural. Claribalte Passos.

Abstract: This article aims to analyze the short story "A maldição do canavial", in Estórias de engenho, by Claribalte Passos, a writer from Pernambuco, in the light of the fantastic. Based on theorists who make it possible to read the text in dialogue with the context, a view is drawn on the supernatural that distorts the character's and the reader's view of reality. In the narrative, the fantastic is linked to episodes of injustice and is configured as a curse, whose manifestations are the inexplicable events in the eyes of reason.

Keywords: Fantastic literature. Supernatural. Claribalte Passos.

Resumen: Este artículo tiene como objetivo analizar el cuento "A maldição do canavial", en Estórias de engenho, del escritor pernambucano Claribalte Passos, a la luz de lo fantástico. Basado en los teóricos que hacen posible leer el texto en diálogo con el contexto, se dibuja una visión sobre lo sobrenatural que distorsiona la visión de la realidad del personaje y del lector. En la narrativa, lo fantástico está vinculado a los episodios de injusticia y se configura como una maldición, cuyas manifestaciones son los eventos inexplicables a los ojos de la razón.

Palabras clave: Literatura fantástica. Sobrenatural. Claribalte Passos.

\section{Introdução}

\footnotetext{
* Mestrando no Programa de Pós-Graduação em Letras (PPGL) da Universidade Federal da Paraíba (UFPB). Pesquisador com bolsa de mestrado vigente no CNPq. http://orcid.org/oooo-0002-6733-5548

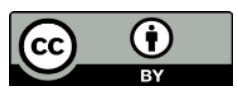


No Nordeste brasileiro, muitas crendices, superstições e histórias sobrenaturais fazem parte do imaginário social. São narrativas que definem o comportamento das pessoas, os medos e as visões de mundo que entram em desacordo com as leis da racionalidade humana. A história da civilização nordestina é marcada por mitos e lendas capazes de determinar a identidade dos espaços e da sociedade, recriando um mundo menos realista do comumente guardado nos registros históricos. Nessa região, entre os locais de tradições e de fantasias, destaca-se o estado de Pernambuco. Nele, a cultura é enriquecida por relatos de testemunhos misteriosos e componentes frutos da imaginação, conferindo à realidade uma racionalização parcial, pois a fabulação do homem provoca uma ambiguidade quanto à conhecida normalidade do cotidiano.

Essas narrativas são transmitidas pela tradição oral, ao longo do tempo, e também fazem parte do inventário da chamada literatura fantástica pernambucana que vigorou ao longo do século XX. Ambientado no imaginário de Recife, destacam-se as obras $A$ emparedada da Rua Nova, de Carneiro Vilela, e Assombrações do Recife velho, de Gilberto Freyre, ambas explorando a capital sob o domínio de forças irreconciliáveis. No interior do estado, a ficção sobrenatural tem como pano de fundo os engenhos do passado, as matas e as pequenas cidades, onde o traço místico e assombrado nasceu junto com a população simples e a vida laboral dos canaviais. Um dos escritores que se dedicam a esse cenário interiorano é Jayme Griz, cujas obras $O$ lobishomem da porteira velha e $O$ cara de fogo revelam as dimensões do fantástico na Zona da Mata.

Há sempre muito que dizer e descobrir sobre os relatos de visagens e acontecimentos estranhos, vivos no imaginário do interior pernambucano. No agreste, ressalta-se Claribalte Passos, escritor que transfigurou o ambiente de Caruaru e redondezas em seus contos e possibilita novos olhares, na estética ficcional e na vida, sobre componentes e fatos insólitos dessa mesorregião. Este artigo se centra na ficção do autor caruaruense, objetivando analisar o conto A maldição do canavial, presente na obra Estórias de engenho, publicada em 1973, à luz do fantástico.

A vivência claribalteana no universo rural faz surgir uma literatura de vínculos com a realidade e traz marcas da memória nas formas de urdidura literária. A leitura analítica do texto acende novas maneiras de demarcações da fantasticidade no discurso 
ficcional, aliado ao contexto social e histórico. Nesse sentido, os pressupostos teóricos que iluminam as discussões propostas se baseiam em uma visão do fantástico definido a partir do conflito existente entre a percepção de realidade intratextual, apoiada nas personagens, e extratextual, baseado no mundo empírico do leitor.

\section{A literatura de Claribalte Passos: transfigurações das lembranças}

A ciência da literatura é, sem dúvida, um lugar de grandes descobertas. A cada investigação sobre ciclos e grupos literários, em determinados espaços, descobrem-se autores e obras que não fazem parte do campo de referências historicamente firmadas, ou seja, do cânone. Quando se oportuniza pesquisar a arte de regiões, encontram-se produções que clareiam novos olhares sobre os componentes estéticos. Assim, ao se adentrar na literatura do interior pernambucano, no século XX, vê-se que os escritores fizeram parte de uma classe artística comprometida em transfigurar para o texto marcas regionais identitárias do lugar em que viveram. Em Caruaru, essa característica se destaca entre os ficcionistas que nasceram na cidade, como Nelson Barbalho, Augusto Tabosa, José Ferreira Condé, Aurélio de Limeira Tejo e Claribalte Passos. Este último, foco do presente artigo, viveu a infância entre os engenhos e experimentou a paisagem cultural do agreste.

A vida literária de Claribalte Passos se inicia aos 18 anos, publicando o primeiro conto no suplemento literário do Jornal do Commercio, em 1941. No ano seguinte, ao deixar Caruaru e ir viver na capital pernambucana, ingressa na Faculdade de Direito do Recife e colabora em diversos periódicos, como o Diário da Manhã e o Diário de Pernambuco. Sua mudança ao Rio de Janeiro, em 1944, marca um novo caminho na trajetória intelectual do escritor, quando passa a escrever em jornais fluminenses e preparar suas obras literárias. A cada narrativa que escreveu, é interessante a importância dada às marcas que fizeram parte de sua história no período vivido entre o céu caruaruense. Isso indica que seus livros plasmam o meio e possuem influências externas que deram sentidos significativos às produções estéticas. 
Entre tantas marcas da contística do autor que aludem à realidade, estão: a paisagem telúrica dos engenhos; o forró entre a fogueira junina; os confrontos políticos do agreste; a riqueza cultural dos bonecos de barro do Mestre Vitalino, junto às variedades comerciais da feira de Caruaru; a vida difícil dos negros nos canaviais; as crendices, o folclore e os acontecimentos insólitos regionais. Essas características remetem a um homem que jamais esqueceu os aspectos humanos e a formação da cultura no interior. Em 1976, no Jornal do Comércio, em Manaus, João Nogueira da Mata destaca a riqueza na literatura de Passos:

Em “ESTÓRIAS DE ENGENHO" estão compaginados vinte e seis capítulos escritos com a técnica de quem já se acha habituado a escrever mensagens válidas. Desses capítulos ressaltam, com apuro, a hintelândia verde referta de paisagens acolhedoras - as águas silenciosas do Ipojuca, a vegetação umbrosa, os variados frutos e as aves canoras. Tudo desperta curiosidade no leitor, principalmente do Extremo-Norte, ou da Amazônia, onde o nordestino tem atuado com grande operosidade, quando tangido pelas secas inclementes.

O mundo encantado do escritor é "GRAÚNA", a propriedade agrícola arroteada sucessivamente pelo bisavô, pelo avô que, curvado dos anos, deixou o patrimônio para o filho Jason. É uma nobilitante sequência de homens que se vincularam aos labores do canavial de Engenho, naturalmente de mistura com os roçados de milho e de mandioca, mas que em momento algum deixaram a rechã sagrada por outras terras distantes. (...) Eis o mundo que Claribalte Passos recriou magistralmente nos escaninhos da memória, deixando entrever em seu livro, com pormenores que, em verdade, despertam o entusiasmo do leitor (MATA, 1976, p. 6).

O paisagismo dos canaviais nas narrativas do escritor caruaruense é uma marca predominante, lugar ligado a sua história e laços familiares. Nos contos, o espaço do engenho "Graúna", entre outros, onde a extensa várzea é atravessada pelo caudaloso rio Ipojuca, alia-se a figuras de donos de terras e trabalhadores que vivem os obstáculos e a fantasia do homem do agreste. Deparar-se com os textos é caminhar por práticas coletivas e expressões da cultura, própria do interior, como se movimentar no embalo intercalado da cadeira de balanço, com o velho cachimbo, tão ciosa das atividades nordestinas, e contemplar os últimos raios de sol tingidos nas folhas dos umbuzeiros. Dessa forma, o ato de lembrar é um movimento pessoal de reinvenção.

Cada ambientação tem como motivação as tradições que cercam a memória de Passos. Assim, vale a pena tomar emprestada brevemente a noção de memória de Le Goff (1990, p. 423-426), como um aspecto crucial, onde se guardam lembranças 
individuais e coletivas e abarca o interior de qualquer ciência, neste caso, a literatura, intervindo não só na ordenação de vestígios, mas na releitura desses vestígios. Nos mergulhos das recordações sociais, há fundamentos que caminham pelo tempo e pela história, ora retraimento, ora transbordando as rememorações.

Das reminiscências nasce o livro Estórias de engenho ${ }^{1}$, cujas páginas ficcionalizam as lembranças da infância no interior pernambucano, com o encantamento da terra, as heranças culturais e o imaginário social do agreste. No prefácio da obra, Luís da Câmara Cascudo (1973) salienta que os contos trazem histórias do povo, cuja morte não teve o poder de sumir com as narrativas, mas de transfigurá-las. Logo, o tapete-mágico dessa transferência é a memória, em que a peregrinação parte do lugar de onde se ausenta. A viagem no imaginário começa a partir do próprio ser e as criações humanas que se erguem, ao longo do tempo, nascem da sensibilidade das origens. O mundo de caruaru, aos olhos de Passos, diz sobre um tempo que não voltará, mas possibilita, na literatura, a saudade de Caruaru no mar de Copacabana (CASCUDO, 1973, p. 11-13).

Diante desse cenário regional, o autor presenteia seus leitores com algumas crendices e acontecimentos insólitos, como almas do outro mundo atrás do tronco da baraúna, a atmosfera assombrada misturada aos cânticos dos grilos nos matagais, visagens e aparições sobrenaturais na Missa-do-Galo, alucinações, lendas e crenças típicas do ambiente silvestre dos engenhos. Esses fatos que desestabilizam a ordem do cotidiano registram, na literatura, um espaço no agreste de Pernambuco que nem sempre refletiu a um realismo ortodoxo e foi habitado por mistérios impenetráveis. Diante dessas desestabilizações dos limites de segurança, a validade dos elementos de percepção da realidade é questionada, visto que a natureza das narrativas do autor caruaruense possui nexo com um mundo social, regido pela linguagem da fantasia.

Nos trilhos dessas ponderações críticas sobre o livro de Passos estão os fatos estruturais ligados à vida. Essa relação do texto literário com o campo social é discutida por Antonio Candido, em Literatura e sociedade (2006). O crítico brasileiro advoga que a obra só está acabada no momento em que repercute e atua, ou seja, no seu vínculo com os fatores sociais. Tendo em vista que a arte é um sistema simbólico de comunicação

\footnotetext{
${ }^{1}$ A obra Estórias de engenho foi vencedora do Prêmio "João Ribeiro", referência nos temas folclóricos, em 1974, da Academia Brasileira de Letras.
} 
do homem, ela recorre ao arsenal de componentes da civilização para seus temas e suas formas de configuração. Desse modo, não é possível deixar de incluir em sua explicação e investigação os elementos do processo comunicativo que circulam em sociedade (CANDIDO, 2006, p. 26-32).

Ainda segundo Candido, a literatura se insere em um movimento dialético que engloba a arte e a realidade em um vasto sistema de conexões entre o autor, a obra e o público. Nessa tríade, o escritor tem uma posição na escala social e se forma em grupos de artistas, desempenhando um grau de influência que diz respeito ao tempo e ao espaço onde vive. As configurações da obra são determinadas por valores históricos, ideologias e sistemas de comunicação que remetem ao seu criador. Já os leitores exprimem as expectativas a respeito do autor e da obra e deliberam julgamentos acerca da estética. Por meio desse aparato de ligações, permanece a essência do fenômeno artístico: compreendido em sua vereda de interação (CANDIDO, 2006, p. 33-49).

Esses pressupostos candidianos reafirmam a condição da literatura em atravessar a vida. As narrativas de Passos não se inserem em um gênero de recordação, mas em uma injeção da realidade e da memória no imaginário. Trata-se de estabelecer um ciclo de confluências entre a fabulação e os aspectos que moldam o olhar do homem sobre o mundo. Os textos, quando tocados pelo viés do campo do fantástico, fazem dos detalhes completamente verossímeis uma oportunidade para a inserção de fenômenos estranhos que moldam a literatura fantástica. No conto A maldição do canavial, em Estórias de engenho, o universo familiar pode revelar um lado obscuro do cotidiano que a razão não consegue explicar.

\section{A vida laboral no engenho: um misto de crueldades}

O dia a dia entre os engenhos é marcado por relações sociais bastante rígidas e por crenças que nascem dessa dureza laboral nos canaviais. Em “A maldição do canavial”, o vento rural parece soprar para os conflitos, os receios e os mitos que cercam esse ambiente. Em síntese, o conto se inicia destacando a natureza rude da personagem 
Antônio Satu, um proprietário de terras inconformado com o fim da escravatura e cruel com os trabalhadores de sua propriedade. A esposa, Dona Olindina, infeliz no matrimônio e descontente com a dureza do marido, decide ir embora. Os miseráveis seviciados do engenho, também fadigados da maldade do patrão, resolvem pedir proteção e vingança ao Preto Velho. O resultado desse clamor é a fúria sobrenatural nascida dos lamentos negros. Em uma noite de tempestade, Satu vê-se diante de acontecimentos e seres insólitos, enquanto os labutadores assistem incrédulos aos fatos e acendem em seus corações os sentimentos de esperança (PASSOS, 1973, p. 53-59).

Inicialmente, são interessantes os aspectos descritivos que mostram a imagem de Satu como um senhor de engenho de índole cruel e mobilizado por devoções religiosas:

\begin{abstract}
Era um homem rude por natureza. Gordo, atarracado, tipo do matuto queimado de sol da zona do brejo, desses que ainda usavam camisa sem colarinho, um tanto desleixado consigo mesmo, a ponto de raramente estar de barba feita. Visceralmente religioso, tinha lá suas superstições e santos preferidos. Analfabeto, de mentalidade tacanha, tratava como verdadeiros escravos aos empregados das terras do "Cana-de-fogo", do qual tanto se orgulhava.

(...) Diziam por lá, que ele já estivera na cidade de Juazeiro, no Ceará, e recebera a benção do "Padim Cirço", o legendário Padre Cícero Romão Batista, o discutido conselheiro-taumaturgo do Sertão, a figura que "deu" patente ao cangaceiro mais temível daquelas bandas, Virgulino Ferreira da Silva, o "Lampião".

(...) Obtuso à compreensão, animalizado em alguns momentos, não podia aceitar que a lei lhe negasse o direito de vida e morte sobre os míseros empregados. Não se conformava com o fim da escravatura. Trabalhador só merecia chicote e uma cuia de feijão com farinha, um caneco d'água, isto mesmo uma vez por dia (PASSOS, 1973, p. 53-54).
\end{abstract}

A personagem é demarcada como um indivíduo ignorante, indiferente à situação de trabalho dos empregados e negando-lhes condições agradáveis de sobrevivência. A insatisfação com a abolição da escravatura revela um aborrecimento pelos atos de violência não estarem respaldados pela lei, mas que não houve interrupção de seu ofício de autoridade do engenho, mantenedora do sistema escravista. Evidentemente, os traços de Satu os transformam em um homem alheio à compaixão humana e embrutecido pelo sadismo, fazendo com que o trabalhador, ainda que alcance legalmente a liberdade, mantenha-se preso a um cotidiano árduo e insalubre. 
Análoga à relação entre Satu e os empregados, a realidade carrega uma história de contínuo sofrimento nos engenhos do interior nordestino, após a Lei Áurea. De acordo com Manuel Correia de Andrade (1963), em A terra e o homem no Nordeste, os escravos foram legalmente libertos, mas continuaram sem assistência governamental, sem terras para cultivar e sem condições de seguir a vida longe das fazendas. Assim, permaneceram trabalhando nas lavouras de cana e se transformaram nos "moradores de condição". Esses trabalhadores se colocavam na tutela do senhor de engenho, principalmente para receberem algum amparo e moradia, porém eram retidos nos campos devido às dívidas com os patrões. A situação, após a abolição, era uma falsa ilusão de liberdade, pois continuaram a habitar a senzala, restringir-se às labutas mais pesadas e viver em condições miseráveis (ANDRADE, 1963, p. 96-109).

No rastro dessas dificuldades sociais, plasmada na história, ambienta-se a narrativa de Passos, cujo senhor de engenho mantém os empregados em situações análogas à escravidão. A brutalidade da personagem é verossímil as barbáries que assolaram os engenhos do interior pernambucano no mundo empírico, pondo em evidência marcas da escuridão e dos sofrimentos que se penetraram nos canaviais. No conto, o regime cruel imposto por Satu parece se contrapor às suas crenças religiosas. Há a devoção ao Padre Cícero, uma figura que carrega uma história de fatos milagrosos e influências sócio-políticas.

Sobre a história do santo, os milagres de Padre Cícero, que lhe custaram a censura eclesiástica devido aos atritos com a Igreja de matriz europeia, renderam-lhe longo desafio de luta religiosa para provar os fenômenos divinos ocorridos no sertão. Apesar de ter sido afastado da igreja e impedido de realizar missas, ele recebeu o apoio popular. Da sua casa, realizava orações e se tornava padrinho de muitas crianças, atitude que lhe rendeu o apelido de "Padim Cirço". Posterior aos desafios de provar os milagres em Juazeiro e aos atritos eclesiásticos, o sacerdote segue a vida política. Nela, entre tantas polêmicas, destaca-se a nomeação não oficial de Lampião como capitão de um exército de jagunços, o valente Capitão Virgulino Ferreira, com objetivo de combater a Coluna Prestes. O cangaceiro, conhecido por ser rígido na disciplina e não perdoar o desrespeito de nenhum de seus subordinados, após ser capturado e morto, tornou-se um símbolo da guerrilha sertaneja (NETO, 2009). 
A narrativa alude a esse episódio de relação política entre Padre Cícero e Lampião, recuperando a prática comum de devoção aos santos que faz parte da cultura e da fé do interior de Pernambuco. A crença da personagem Satu, cuja casa tinha retratos de santos tradicionais e desconhecidos, contraria sua tirania diante dos empregados que lhe cercam. Ele se destaca como um típico senhor de engenho ambicioso, extraindo dos canaviais mais do que sua agricultura, conseguindo o temor dos "ex-escravos" e a estranheza diante das circunstâncias. Nem mesmo sua esposa se livrou da doentia brutalidade do marido:

Dona Olindina, com quem vivia maritalmente, nem sequer ousava arriscar um tímido olhar de reprovação às atitudes intempestivas do "marido". Compreendia, por experiência própria, a inutilidade de qualquer protesto ou pedido seu, por menor que fosse se extinguiria sem eco, como um repentino sopro de brisa se estabelecendo contra olhos abertos, sem nenhuma reação.

A mulher vivia choramingando infelicidade, pelos cantos sombrios da CasaGrande, rolando as contas do seu "terço" com os dedos calejados, ásperos de tanto trabalho, numa prece íntima de tênue esperança no amanhã. Cerrava os olhos, quando espichava aquele corpo moído pelas dores da enorme fadiga diária, e via contra as pálpebras o sofrimento dos pobres cortadores de cana do engenho, o suor a inundar-lhes o rosto marcado pela resignação (PASSOS, 1973, p. 55-56).

Dona Olindina compreendia os sofrimentos dos trabalhadores por vivenciar dentro da casa-grande a rispidez do marido. Típica senhora dos engenhos caruaruenses, ela tornava-se mais próxima dos empregados e respirava a sociedade patriarcal no mundo rural do agreste. A autoridade moral, o privilégio social e o controle das terras eram de Satu, restando-lhe apenas a frigidez sentimental vivida maritalmente. As suas insistências em tentar mudar as atitudes do senhor de engenho são fracassadas e resultam na reação em fugir daquele lugar, onde prevalece certo tipo de autocracia e submissão.

Historicamente, as relações de gênero nos engenhos foram marcadas por desigualdades, hierarquia e tensões. Ainda que mais bárbara nas ex-escravas e nas mulheres mais pobres, a força patriarcal exercia sua crueza na casa-grande. A função da mulher do senhor do engenho esteve bastante relacionada à manutenção dos valores familiares, às devoções religiosas, à procriação e às responsabilidades sobre as empregadas e suas tarefas domésticas. Desse modo, a figura feminina era criada em um 
ambiente rigorosamente patriarcal, primeiro através da tirania do pai, substituída pela tirania do marido (FREYRE, 2005). No conto, Dona Olindina vive o abuso exercido por Satu pelos cantos sombrios do engenho Cana-de-fogo. Os seus dedos calejados em oração são insuficientes para que ocorram modificações na conduta do esposo, motivando-a a abandonar o chefe da casa.

Apesar da dureza e impiedade, há sempre algo que o homem teme. Por essa razão, o limite da autoridade de Satu nos canaviais são as forças misteriosas, sobrenaturais e invisíveis, as quais não se conseguem ter domínio. Ele não saia à noite, com medo das almas dos escravos enterrados no engenho, onde relatos de assombrações, maldições, lendas e crendices davam calafrios ao senhor. Do mesmo modo que a esposa, os trabalhadores, inconformados com tanta crueldade, reagem contra o patrão e apelam para figuras místicas, habitantes do desconhecido. Esses seres, quando passam a irromper no cotidiano, mostram seus poderes de amedrontar, causar medo, provocar terror e interromper a existência em vida. Da maldade, nas terras do interior, originamse os motivos que levam às origens das aparições e dos acontecimentos fantásticos.

\section{A justiça do fantástico: a maldição}

Podem-se dominar aspectos do cotidiano, mas as leis desconhecidas do submundo não conseguem ser comandadas pelo poder humano. Na narrativa, os trabalhadores do Cana-de-fogo decidem pedir proteção e vingança ao Preto Velho, acionando as forças sobrenaturais:

De outra parte, aos míseros trabalhadores seviciados do engenho "Cana-defogo" a única alternativa de salvação estava em pedir proteção e vingança ao "Preto Velho", supliciado há anos, num valado do Canavial. Fora surrado impiedosamente por Satu até a morte. Afirmava-se, no lugar, que à noite os gritos de dor do pobre homem eram sempre ouvidos e isto fazia com que muitos que por ali passavam ficassem de cabelos completamente eriçados. Daí, nascera, a maldição do canavial.

Sim, morreriam por fogo, sem apelação todos aqueles que insistissem em ser maus e indiferentes ao mínimo gesto humanitário para com o pessoal do velho engenho. Ninguém, porém, se valia do feitiço ou beberagem oriunda de 
candomblés e catimbós, no sentido de fazer "justiça", sob o impacto terrível de um temporal (PASSOS, 1973, p. 56-57).

Nasce do pedido dos empregados a revelação de uma maldição dos engenhos, cujo resultado é uma justiça aos homens, com práticas de violência contra os trabalhadores. Esse poder sobrenatural é oriundo do sofrimento de um pobre canavieiro do passado que viveu a impiedosa crueldade do patrão na propriedade de terra. Em reposta ao ritual de suplício, com raízes nas religiões de matriz africana, seguidas com frequência pelos negros que viviam nas fazendas, uma forte tempestade anuncia as ocorrências insólitas e os pedidos de justiça a serem atendidos.

Frequente aspecto em textos da literatura fantástica, a maldição pode se apresentar de diversas maneiras, como uma imprecação ou justiça sobrenatural contra alguém. Ao longo da história da humanidade, aparece em diversos registros, como na Bíblia, onde essa ação simbólica divina remete aos pecados. Ademais, associada à feitiçaria e à bruxaria em documentos que falam da fantasia das civilizações, ao longo dos séculos, representou a justiça, a maldade, a fúria e o julgamento diante das atitudes dos homens. O que existem em comum nessas práticas é a vinculação com o além, onde são invocados seres e pedidos do mundo desconhecido e repleto de segredos, cuja compreensão humana não alcança.

No conto, os ventos fortes da tempestade sopravam para a maldição na casagrande, efeito do pedido dos trabalhadores e justiça às condições miseráveis no labor do engenho. Sob os incomuns trovões e a atmosfera fria, o homem rude daquelas terras benzia-se a cada minuto segurando a medalha abençoada por Padre Cícero. Logo, Satu se viu diante de acontecimentos insólitos e figuras fantasmagóricas em seu dormitório, ocupando dentro de si os receios, calafrios e incompreensões na presenta de fatos assombrados:

Dentro do negrume do cômodo, que lhe servia de dormitório e agora de esconderijo, distinguia muito mal apenas certas cintilações. Ou seriam faíscas? Tudo trepidava sob a ação devastadora do vendaval. Tateou na escuridão buscando encontrar o lampião de querosene. Nada. Experimentava esquisita sensação de desamparo. E os pés, por que formigavam tanto? Seria "cãimbra"? Súbito, desmoronou parte do teto, despregando-se ripas, caibros, telhas. Um verdadeiro pandemônio no interior do quarto. Rolos de fumo esvoaçavam de um lado a outro, formando macabras figuras, dando a impressão que 


\begin{abstract}
"mangavam" dele, ali, inerte, sucumbindo, aterrado, sem ação. Estalidos contínuos, semelhavam uma conversa de almas de outro mundo, entremeados por quedas de argamassa despregada dos tijolos mal cozidos.

(...) Valeu-se de um ingente esforço tentando uma explicação para o que lhe acontecia. De novo, as faíscas, as gargalhadas satânicas das figuras estranhas, desdenhosas, tirânicas, avassaladoras, impiedosas (PASSOS, 1973, p. 57-58).
\end{abstract}

No quarto de Satu, os acontecimentos e seres sobrenaturais que são instaurados passam a subverter a visão de cotidiano. Uma atmosfera misteriosa e sombria é criada, desde a forte tempestade noturna, aos efeitos de desordem e assombro dentro do dormitório, para que aos poucos os efeitos decorrentes da irrupção do fantástico tenham o efeito desejado: desestabilizar as normas que regem a racionalidade. As sensações sentidas pelo senhor de engenho são reflexos do poder do sobrenatural em causar a insegurança e a perplexidade diante de eventos desconhecidos e fenomenologias contraditórias. As modificações no espaço se aliam às macabras figuras, às gargalhadas satânicas e aos seres estranhos que, em nenhum momento, fazem parte do dia a dia no engenho Cana-de-fogo. Assim, a natureza fantástica da narrativa nasce de uma maldição e se desenvolve na ruptura com as normas socialmente aceitas.

Tanto a personagem quanto o leitor são incorporados nesse universo de estranhezas que estava dominado pelas leis sociais de hostilidade e passa a ser regido por situações perturbadoras no curso do cotidiano transgredido. Qualquer tentativa de compreensão dos fatos não tem sucesso, pois ambos estão imersos em episódios da ordem do sobrenatural que se contrapõem ao real. Essa demarcação alude às proposições de Todorov (1975), no livro seminal Introdução à literatura fantástica. Conforme o crítico búlgaro, a presença de um ser ou acontecimento sobrenatural marca os sinais da presença do fantástico. O cerne do gênero ocupa o tempo da incerteza, em que personagem e leitor não chegam a um denominador comum, até o fim da aventura, sobre os fatos serem verdadeiros ou frutos da imaginação. Quando se escolhe uma das duas respostas, caminha-se para dois gêneros vizinhos: o estranho, na procura de explicações racionais para o perigo fantástico, e o maravilhoso, à medida que os aspectos insólitos são naturalizados (TODOROV, 1975, p. 29-63).

Guiada pelos assombros e pela fantasticidade, a narrativa transforma a espacialidade do quarto em um lugar habitado por seres malignos e deturpa qualquer 
noção de realidade estável. Em A ameaça do fantástico, David Roas (2014) assegura que a natureza do gênero se nutre dessa ideia de um cotidiano estável e ordenado por leis fixas que, com a irrupção do sobrenatural, define-se pela deturpação e violação dessas regras. Torna-se importante a presença do leitor nessa jornada, pois a normalidade da vida passa a ser confrontada mediante as inúmeras realidades paralelas: o mundo concreto e o irreal, irreconhecível e inexplicável. Nessa perspectiva, além da hesitação, o fantástico deve se nutrir dos traços de verossimilhança para que se desmoronem todas as certezas firmadas (ROAS, 2014, p. 131-134).

Tudo acontece com a presença de assombrações e a problematização dos limites da realidade e da irrealidade. Ao leitor, no início da narrativa, é oferecido um espaço dos engenhos semelhante ao encontrado no seu mundo empírico, onde traços sociais e históricos da cultura no interior pernambucano são rapidamente identificados. No decorrer da leitura, duas estranhezas são percebidas: a primeira, relacionada à crueldade do senhor de engenho, e a segunda, estabelecendo um sistema de valores de uma comunidade totalmente invertidos e com nexo no sobrenatural. Nesta ficção de Passos, o fantástico toma como ponto de apoio para a irrupção o suplício dos trabalhadores, validado por uma maldição que, quando decretada, introduz no ambiente a perplexidade de fatos insólitos, em que a razão está sempre condenada ao fracasso.

Frequentemente, em situações de caos, o ser humano passa a demonstrar sentimentos de maior fragilidade. Isso não acontece com a personagem Satu, pois mesmo vivenciando todas as circunstâncias de terror e de agonia, a rudeza de suas emoções não o faz lembrar-se de Dona Olindina e de Sabino, este último sendo um provável filho ou parente que ingressara em um seminário longe do engenho. Já os empregados assistiam incrédulos, diante da vivenda, àquela desordem e obscuridade na casa-grande, mas possivelmente com outro sentimento dentro dos corações:

Defronte à vivenda destruída pelo temporal, cabisbaixos, incrédulos diante do quadro tétrico os trabalhadores se entreolhavam, talvez sorrindo por dentro, entoando a uma só voz a quadrinha:

"Meu São Benedito

É santo de preto;

Ele bebe garapa.

Ele ronca no peito!" 
E repetindo algumas vezes a pequena cantiga, aqueles homens rudes e simples se deixaram ficar ali, cismando, debruçando ilusões sobre novas esperanças (PASSOS, 1973, p. 59).

Os trabalhadores ficam surpresos com os acontecimentos. Ao mesmo tempo, parece ecoar dentro deles o alívio por se vingarem do patrão e respirarem uma provável libertação da violência sofrida no engenho. Graças à justiça oriunda do sobrenatural, é possivel enxergar luzes de esperança em um mundo de injustiças. Ademais, menos que fortuita é a presença de São Benedito na quadrinha falada por eles, visto que corresponde a um santo católico negro. Tradicionalmente venerado pelos labutadores negros que viviam nos canaviais, esse santo reflete a experiência do sincretismo religioso na história da escravatura, com foco na contiguidade de rituais sem perseguições.

O que se percebe são os vínculos existentes entre as lutas dos empregados com os aspectos que se orientam no domínio do fantástico. A mitologia cristã e as crenças de elementos do submundo fazem parte do cenário de lendas e tradições do imaginário popular. Nesse sentido, o sobrenatural se apropria dos suplícios dos trabalhadores, vindos do misticismo negro, para exercer seu aspecto de causar estranheza ante os episódios que desestabilizam a ordem do cotidiano. No mundo verossímil dos engenhos, onde a paisagem alude a um ambiente rural do interior de Pernambuco, leis incógnitas e obscuras surgem para desestabilizar as formas de compreensão da realidade intra e extratextual.

\section{Considerações finais}

Os propósitos deste artigo caminharam em uma discussão que oportunizou refletir sobre o texto aliado ao contexto, traçando um paralelo que permite perceber o fantástico como um gênero capaz de subverter a visão de real, tanto no universo da personagem, quanto no mundo do leitor. O conto de Claribalte Passos viabiliza configurações do imaginário na ambientação dos engenhos do interior pernambucano, onde crendices se ligam diretamente às histórias de sofrimento e injustiças sociais. As 
forças desconhecidas do sobrenatural se apresentam como uma maldição e provocam a transgressão das ilusões de um cotidiano normal e estável. Certamente, os canaviais ainda guardam muitos segredos, lendas, superstições e assombrações a serem investigadas na contística do autor caruaruense, ligados a sua vida nas terras do Nordeste, onde a fantasia é o caminho de aventura seguido pelos indivíduos.

\section{Referências}

ANDRADE, Manuel Correia de. A terra e o homem no Nordeste. São Paulo: Editora Brasiliense, 1963.

CANDIDO, Antonio. Literatura e sociedade. $9^{\circ} \mathrm{ed}$. Rio de Janeiro: Ouro sobre Azul, 2006. CASCUDO, Luís da Câmara. Prefácio. In: PASSOS, C. Estórias de engenho. Rio de Janeiro: Coleção canavieira, 1973.

FREYRE, Gilberto. Casa-Grande E Senzala: formação da família brasileira sob o regime de economia patriarcal. $50^{\circ}$ ed. São Paulo: Global, 2005.

LE GOFF, Jacques. História e memória. Trad. Bernardo Leitão. Campinas: Editoria da UNICAMP, 1990.

NETO, Lira. Padre Cícero: Poder, fé e guerra no sertão. São Paulo: Companhia das letras, 2009 .

MATA, João Nogueira da. Estórias de engenho. Jornal do Comércio, n. 22057 Manaus, 11 jan. 1976. p. 6.

PASSOS, Claribalte. Estórias de engenho. Rio de Janeiro: Coleção canavieira, 1973.

ROAS, David. A ameaça do fantástico: aproximações teóricas. Tradução de Julián Fuks. São Paulo: Editora Unesp, 2014.

TODOROV, Tzvetan. Introdução à literatura fantástica. São Paulo: Perspectiva, 1975.

Recebido em 29/04/2020.

Aprovado em 19/09/2020. 